\title{
Simultaneous determination of renal function biomarkers in urine using a validated paper-based microfluidic analytical device
}

\author{
Eduardo Luiz Rossini ${ }^{a}$, Maria Izabel Milani ${ }^{a}$, Emanuel Carrilho ${ }^{\text {b }}$, Leonardo Pezza ${ }^{a}$, \\ Helena Redigolo Pezza a, * \\ a Instituto de Química, Universidade Estadual Paulista “Julio de Mesquita Filho"- UNESP, R. Prof. Francisco Degni 55, P.O. Box 355, 14801-970, Araraquara, \\ SP, Brazil \\ b Instituto de Química de São Carlos, Universidade de São Paulo, Av. Trabalhador São-carlense, 400, 13566-590, São Carlos, SP, Brazil
}

\section{H I G H L I G H T S}

- Simple, fast, easy to use, and inexpensive method to quantify renal biomarkers.

- Novel validated $\mu$ PADs for simultaneous creatinine and uric acid determination in urine.

- Determination of creatinine and uric acid at low, high, and normal levels in urine.

\section{A R T I C L E I N F O}

\section{Article history:}

Received 13 July 2017

Received in revised form

27 September 2017

Accepted 19 October 2017

Available online 27 October 2017

\section{Keywords:}

Paper-based microfluidic analytical device $(\mu \mathrm{PAD})$

Renal function

Creatinine

Uric acid

Urine

Digital image

\section{G R A P H I C A L A B S T R A C T}

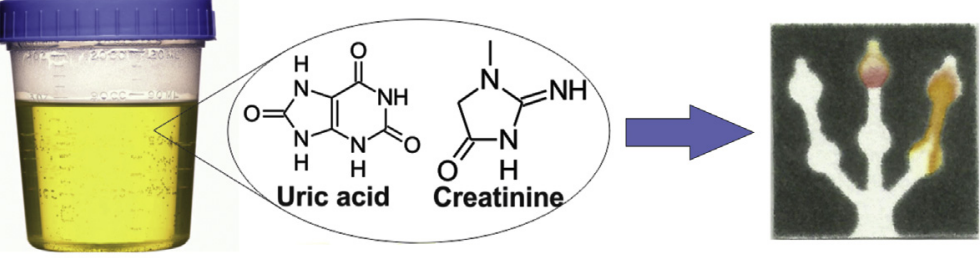

\begin{abstract}
A B S T R A C T
In this paper, we describe a validated paper-based microfluidic analytical device for the simultaneous quantification of two important biomarkers of renal function in urine. This paper platform provides an inexpensive, simple, and easy to use colorimetric method for the quantification of creatinine (CRN) and uric acid (UA) in urine samples. The microfluidic paper-based analytical device ( $\mu$ PAD) consists of a main channel with three identical arms, each containing a circular testing zone and a circular uptake zone. Creatinine detection is based on the Jaffé reaction, in which CRN reacts with picrate to form an orangered product. Uric acid quantification is based on the reduction of $\mathrm{Fe}^{3+}$ to $\mathrm{Fe}^{2+}$ by $\mathrm{UA}$, which is detected in a colorimetric reaction using 1,10-phenanthroline. Under optimum conditions, obtained through chemometrics, the concentrations of the analytes showed good linear correlations with the effective intensities, and the method presented satisfactory repeatability. The limits of detection and the linear ranges, respectively, were $15.7 \mathrm{mg} \mathrm{L}^{-1}$ and $50-600 \mathrm{mg} \mathrm{L}^{-1}$ for CRN and $16.5 \mathrm{mg} \mathrm{L}^{-1}$ and $50-500 \mathrm{mg} \mathrm{L}^{-1}$ for UA. There were no statistically significant differences between the results obtained using the $\mu \mathrm{PAD}$ and a chromatographic comparative method (Student's $t$-test at $95 \%$ confidence level).
\end{abstract}

(C) 2017 Elsevier B.V. All rights reserved.

\section{Introduction}

The kidneys play vital roles in the human body. They fulfill excretory, regulatory, and endocrine functions, and are responsible

\footnotetext{
* Corresponding author.

E-mail address: hrpezza@iq.unesp.br (H.R. Pezza).
}

for osmotic balance, regulation of blood pressure, excretion of endocrine hormones, and elimination of toxic substances. The loss of kidney function, characterizing renal failure, may be asymptomatic until about $50 \%$ of the kidney function has been compromised. Therefore, since renal insufficiency is a silent disease, the only way to evaluate renal function is by the measurement of biomarkers. Two widely used and important biomarkers are creatinine and uric acid. The concentrations of these compounds in 
urine can provide important information about renal function, enabling early diagnosis and increasing the possibility of cure or delay of the disease.

Creatinine (CRN) is spontaneously produced in the metabolism of muscle contraction from creatine and phosphocreatine. It is excreted by the kidneys and is not available to the organism. Since the rate of excretion of creatinine is relatively constant, it is an important clinical marker for renal function, because a decrease in the concentration found in urine is associated with deterioration of renal function [1].

Creatinine determination is traditionally performed by Jaffé's method, which is simple, fast, cheap, and easy to perform. In this test, alkaline picrate reacts with creatinine to form an orange-red product that is measured spectrophotometrically. Other current methods include HPLC-MS/MS [2], HPLC-DAD [3,4], spectrophotometry [5], spectrophotometry using a portable microfluidic system [6], and electrophoresis with electrochemical [7], UV [8], and colorimetric detection [9].

Uric acid (UA) is the final product derived from catabolism of purine bases (adenosine and guanine). Hyperuricemia, associated with high concentrations of uric acid, causes gout and has been correlated with many diseases including diabetes, Lesch-Nyan disease, high blood pressure, and heart disease [10]. Patients with hyperuricemia show a higher incidence of renal failure [11], demonstrating the importance of uric acid as a biomarker.

Analytical procedures for the measurement of uric acid include HPLC-DAD [3,4], electrophoresis with UV detection [8], spectrophotometry with chemometric tools [12], electrochemical methods [13], colorimetric detection with multiple indicators [14], enzymatic reaction [15], and gold nanoparticles [16]. Only methods that involve separation techniques, such as chromatography $[3,4]$ and electrophoresis [8], are able to determine both analytes simultaneously. However, these techniques involve the use of large volumes of toxic organic solvents, produce substantial amounts of waste that may be dangerous to the operator and the environment [17], and require laborious clean-up steps.

Paper is an emerging solid support that can be used in chemical and biological analyses, due to its widespread availability, low cost, and provision of a high-contrast background for colorimetric detection [18,19]. Microfluidic paper-based analytical devices ( $\mu$ PADs) are simple systems for use in diagnostic bioanalyses. The advantages of this platform over conventional methods of analysis are numerous including simplicity, portability, and disposability. The $\mu$ PADs present low cost and are easy-to-use, with interesting features as compatibility with biological samples, low reagent consumption, small sample volume, the possibility to integrate many analytical determinations using one device, safe disposable by incineration and many fabrication methods [20,21]. Moreover, the control of fluid transport by capillarity and evaporation does not require an external power source [22].

This inexpensive diagnostic platform may be employed in remote villages or other areas where it is difficult to access laboratory infrastructure and trained personnel, due to its simplicity and minimal production cost. For this reason, techniques have been developed for the detection of several species relevant for disease prevention and diagnosis, including glucose [22], protein [22], nitrite [23], aldehydes [24], beta-hydroxybutyrate [25], uric acid [15], and cholesterol [26].

In the present work, a $\mu$ PAD was constructed and two optimized and validated methods were developed for the simultaneous quantification of two biomarkers in urine, namely creatinine and uric acid, using Jaffé's method and a $\mathrm{Fe}^{3+} / 1,10$-phenanthroline method, respectively. The proposed analytical device can be used to evaluate renal function and to help prevent kidney failure, offering low cost, simplicity, and portability.

\section{Materials and methods}

\subsection{Reagents and standard solutions}

All reagents used were analytical grade. Solutions and dilutions were made using deionized water $(18.2 \mathrm{M} \Omega \mathrm{cm}$ ) obtained from a Milli-Q system (Millipore). Standard solutions of anhydrous creatinine (Sigma-Aldrich) and uric acid (Sigma-Aldrich) were prepared in deionized water and in $0.05 \mathrm{~mol} \mathrm{~L}^{-1} \mathrm{NaOH}$ (Sigma-Aldrich), respectively, in the latter case in order to avoid precipitation of uric acid. All acid and alkaline solutions were standardized as described in the literature [27].

The chromogenic reagent employed in the creatinine analysis consisted of $0.010 \mathrm{~mol} \mathrm{~L}^{-1}$ picric acid (Merck) in $1.00 \mathrm{~mol} \mathrm{~L}^{-1} \mathrm{NaOH}$. The two reagents used in the uric acid analysis were $0.0600 \mathrm{~mol} \mathrm{~L}^{-1}$ 1,10-phenanthroline (Sigma-Aldrich) with $0.530 \mathrm{~mol} \mathrm{~L}^{-1}$ anhydrous sodium acetate (Sigma-Aldrich) in a 50:50 ethanol (Tedia) and water medium, and $0.0450 \mathrm{~mol} \mathrm{~L}^{-1} \mathrm{Fe}\left(\mathrm{NO}_{3}\right)_{3} \cdot 9 \mathrm{H}_{2} \mathrm{O}$ (SigmaAldrich) in $0.25 \mathrm{~mol} \mathrm{~L}^{-1} \mathrm{H}_{2} \mathrm{SO}_{4}$ (Sigma-Aldrich). Amaranth was purchased from Sigma-Aldrich.

The solutions used in the study of interferences were prepared using a ratio of 1:1 (analyte/interferent) for acetone (Quemis), uric acid (Sigma-Aldrich), ascorbic acid (Merck), albumin (Across Organics), creatine, creatinine (Sigma-Aldrich), glucose (Chemco), sodium pyruvate (Merck), $\mathrm{CaCl}_{2} \cdot 2 \mathrm{H}_{2} \mathrm{O}$ (Reagen), $\mathrm{KCl}$ (Synth), $\mathrm{KH}_{2} \mathrm{PO}_{4}$ (Merck), $\mathrm{Na}_{2} \mathrm{SO}_{4}$ (Merck), $\mathrm{NaCl}$ (Mallinckrodt), and $\mathrm{NH}_{4} \mathrm{Cl}$ (Merck). Analyte/interferent ratios of 25:1 and 1:10 were used for bilirubin (Merck) and urea (Sigma-Aldrich), respectively.

Three synthetic urine samples were prepared as described by Laube et al. [28], containing $1.10 \mathrm{~g} \mathrm{~L}^{-1} \mathrm{CaCl}_{2} \cdot 2 \mathrm{H}_{2} \mathrm{O}, 2.93 \mathrm{~g} \mathrm{~L}^{-1} \mathrm{NaCl}$, $2.25 \mathrm{~g} \mathrm{~L} \mathrm{~L}^{-1} \quad \mathrm{Na}_{2} \mathrm{SO}_{4}, \quad 1.40 \mathrm{~g}^{-1} \quad \mathrm{KH}_{2} \mathrm{PO}_{4}, \quad 1.60 \mathrm{~g} \mathrm{~L}^{-1} \quad \mathrm{KCl}$, $1.00 \mathrm{~g} \mathrm{~L}^{-1} \mathrm{NH}_{4} \mathrm{Cl}$, and $25.00 \mathrm{~g} \mathrm{~L}^{-1}$ urea. Uric acid and creatinine were added to the synthetic urine in appropriate concentrations. Four natural urine samples from healthy and drug-free people were collected in clean containers. The $\mathrm{pH}$ of all samples were adjusted to between pH 8 and 9 with $10 \mathrm{~mol} \mathrm{~L}^{-1} \mathrm{NaOH}$ solution to avoid uric acid precipitation [1]. In relation to the proposed analysis, the urine samples were diluted 3-fold with deionized water. For the natural urines, air was bubbled through the sample for $20 \mathrm{~min}$.

\subsection{Fabrication and preparation of the $\mu P A D$}

The configuration of the $\mu$ PAD employed in this work was similar to that reported previously [23], with some modifications. CorelDRAW X5 was used to design the $\mu$ PAD. The analytical device used consisted of a main channel with three identical arms, each containing a circular testing zone and a circular uptake zone. The final dimensions of each device were $19 \times 19 \mathrm{~mm}$, with $4 \mathrm{~mm}$ width for the main channel, $2 \mathrm{~mm}$ width for the arms, and $4 \mathrm{~mm}$ diameters for the testing and uptake zones. The design was printed on a Whatman No. 1 filter paper with wax toner (Genuine Xerox Solid Ink Black) using a wax printer (Xerox Phaser 8560), as described by Carrilho et al. [29]. After printing, the paper was heated at $120^{\circ} \mathrm{C}$ for $120 \mathrm{~s}$ for formation of the hydrophobic barriers.

After printing and heating, the $\mu \mathrm{PAD}$ was cut into $19 \times 19 \mathrm{~mm}$ pieces. For creatinine determination, a $2-\mu \mathrm{L}$ aliquot of a solution of $0.1 \mathrm{~mol} \mathrm{~L}^{-1}$ picric acid in $1.0 \mathrm{~mol} \mathrm{~L}^{-1} \mathrm{NaOH}$ was spotted onto the uptake zone. For uric acid determination, a $2 \mu \mathrm{L}$ aliquot of a solution containing 1,10-phenanthroline $\left(0.06 \mathrm{~mol} \mathrm{~L}^{-1}\right)$ and acetate $\left(0.53 \mathrm{~mol} \mathrm{~L}^{-1}\right)$ was added to the uptake zone, and a $2 \mu \mathrm{L}$ aliquot of a solution of $\mathrm{Fe}^{3+}\left(0.45 \mathrm{~mol} \mathrm{~L}^{-1}\right)$ in $\mathrm{H}_{2} \mathrm{SO}_{4}\left(0.25 \mathrm{~mol} \mathrm{~L}^{-1}\right)$ was spotted onto the testing zone. 


\subsection{Method of analysis}

For the analysis of creatinine and uric acid, a $10-\mu \mathrm{L}$ aliquot of the sample or standard solution was transferred to a Petri dish. With the analytical device in a vertical orientation, the main channel was placed in contact with the solution until the hydrophilic zones were filled by capillarity. The $\mu \mathrm{PAD}$ was then heated for $50 \mathrm{~s}$ using a domestic hair dryer set at minimum power $\left(61.1 \pm 0.4^{\circ} \mathrm{C}\right)$. For semiquantitative analysis, the color developed in the testing zone was compared with a color palette. For quantitative determination, the device was digitized and the intensity of the green color (RGB format) obtained in both reactions was determined using Image ${ }^{\mathbb{R}}$ software. The effective intensity of the green color $\left(A_{G}\right)$ was calculated as $A_{G}=-\log \left(G_{S} / G_{B}\right)$, as defined by Abbaspour [30], where $G_{S}$ and $G_{B}$ are the green color intensities of the sample and the blank, respectively. The effective intensities could be used to quantify creatinine and uric acid using the analytical curves.

\subsection{Experimental design}

Experimental design methodology was used to determine the optimal experimental conditions for the spot tests. The circular hydrophobic barriers (15 $\mathrm{mm}$ diameter and $0.75 \mathrm{~mm}$ thickness) were produced similarly to a method of the $\mu$ PAD described previously [29]. In the creatinine spot test, $15 \mu \mathrm{L}$ of creatinine reagent was spotted, followed by $15 \mu \mathrm{L}$ of creatinine solution. For uric acid determination, $10 \mu \mathrm{L}$ of iron(III) solution was spotted, followed by $10 \mu \mathrm{L}$ of uric acid and $10 \mu \mathrm{L}$ of 1,10-phenanthroline solutions. After deposition of the solutions, the papers were heated using a domestic hair dryer at minimum power. The measurements were performed using digital images.

\subsection{Comparative method}

The results obtained by the proposed method were compared with analyses using the comparative HPLC methodology described in the literature [3]. The experimental conditions were as follows: ODS-BP column $(250 \mathrm{~mm} \times 4.6 \mathrm{~mm}, 5 \mu \mathrm{m})$ with an internal ODS-BP guard column; $50 \times 10^{-3} \mathrm{~mol} \mathrm{~L}^{-1} \mathrm{NaH}_{2} \mathrm{PO}_{4}$ (Merck) and methanol (J. T. Baker) (95:5) as the mobile phase; flow rate of $0.8 \mathrm{~mL} \mathrm{~min}^{-1}$; run time of $15 \mathrm{~min}$; injection volume of $20 \mu \mathrm{L}$; DAD detector with a fixed wavelength of $210 \mathrm{~nm}$; column temperature of $25^{\circ} \mathrm{C}$.

Urine samples were diluted 5-fold with the mobile phase and the proteins were precipitated by centrifugation (Universal 320R, Hettich) at $6000 \mathrm{rpm}$ for $10 \mathrm{~min}$. The supernatants were diluted 3fold with the mobile phase. Samples were filtered through a 0.45$\mu \mathrm{m}$ membrane and submitted to analysis by HPLC.

\section{Results and discussion}

\subsection{Design of the $\mu P A D$}

\subsubsection{Hydrophilic channel width and diameter of the zones}

The design of the analytical device developed in this work was similar to those described by Martinez et al. [31] and Bhakta et al. [23]. The ascent velocity of the amaranth dye solution was initially faster and decreased with distance, because the volume of evaporated solution became progressively larger. The ascent rate was slower for channels with smaller widths, due to greater resistance to passage of the solution through the paper [32]. However, a greater hydrophilic channel width increased the sample volume. Therefore, a width of $2 \mathrm{~mm}$ was selected, which provided intermediate ascent velocity and sample volume, without requiring many samples and a long time to fill the entire channel.

The circular format of the uptake and test zones resulted in dependence only on the diameter. Increase in the diameters of the zones increased the volumes of reagent and sample required, and here a $4 \mathrm{~mm}$ diameter was selected for use in the subsequent analyses, which provided good color uniformity without excessive reagent and sample volumes. It was observed that a prolongation after the test zone provided a better distribution of staining in the test zone in the case of creatinine, while the area of the color reaction increased in the case of uric acid. The final design of the analytical device used consisted of a main channel with three identical arms, two arms for uric acid and creatinine determination and the third to determine if the sample color interfere in the analysis. Each arm with a circular testing zone and a circular uptake zone. The final dimensions of the device were $19 \times 19 \mathrm{~mm}$, with a $4 \mathrm{~mm}$ width for the main channel, $2 \mathrm{~mm}$ widths for the arms, and $4 \mathrm{~mm}$ diameters for the testing and uptake zones (Fig. 1).

An amaranth dye solution was used to determine the volume absorbed by the device, and around $10 \mu \mathrm{L}$ was found to be sufficient to fill all the hydrophilic channels. The volume of water absorbed by the device was $10.3 \pm 0.7 \mu \mathrm{L}$ at $25{ }^{\circ} \mathrm{C}(\mathrm{n}=10)$. Therefore, it was possible to perform the analysis without using a micropipette, because the devices absorbed an almost constant volume of sample. Although the results without a micropipette showed a certain dispersion, this alternative still could be used in quantitative analysis. This feature should make the technique attractive for practical use in remote regions where micropipettes may not be available for dispensing accurate volumes.

\subsubsection{Non-specific interactions of analytes with the device}

A concern when using a $\mu$ PAD is that the analyte could be retained nonspecifically in the paper, without becoming evenly distributed (analogously to a chromatographic separation). In order to determine whether the analytes produced stains at the beginning of the device, or whether there was uniform distribution, a device consisting of only one channel, without any zones, was placed in contact with an analyte solution that filled the entire length of the channel. After drying, the channel was divided into two identical halves that were transferred to different tubes, together with $20 \mu \mathrm{L}$ of chromogenic reagent and $1 \mathrm{~mL}$ of deionized water. For the determination of creatinine, the papers were incubated in the tubes at $35^{\circ} \mathrm{C}$ for $15 \mathrm{~min}$ [33]. The absorbance values were recorded with a spectrophotometer, using wavelengths of $500 \mathrm{~nm}$ for creatinine and $510 \mathrm{~nm}$ for uric acid. Statistical comparison of the results resulted in $t$-test values that did not exceed the critical value (4.303, at the 95\% confidence level and with two degrees of freedom), showing that the analytes were distributed evenly throughout the device.

\subsection{Uric acid method}

The determination of uric acid was based on the reducing property of the analyte. The $\mathrm{Fe}^{2+}-1,10$-phenantholine complex is

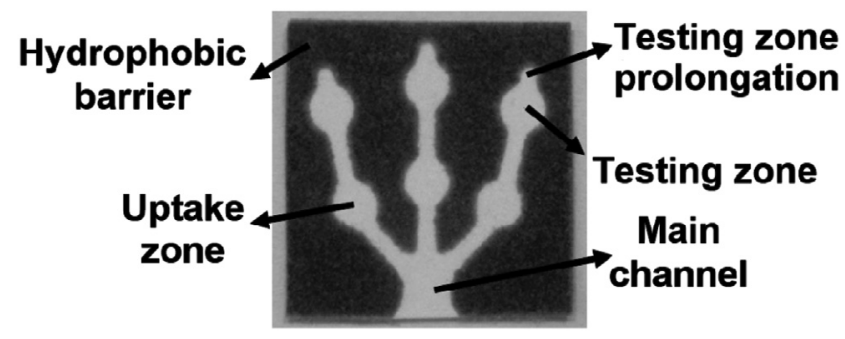

Fig. 1. Design of the analytical device employed for creatinine and uric acid determinations. 
well known and is described in the literature [34] as presenting a red color. The complex between $\mathrm{Fe}^{3+}$ and 1,10-phenanthroline has a pale yellow color, so the reaction used for the analysis was based on the reduction of $\mathrm{Fe}^{3+}$ to $\mathrm{Fe}^{2+}$ by uric acid and complexation with 1,10-phenanthroline.

The $\mathrm{Fe}^{2+}-1,10$-phenanthroline complex stoichiometry is $1: 3$ (metal:complexing agent), while the ratio between uric acid and $\mathrm{Fe}^{3+}$ is not known. The latter was determined using Job's method (or method of continuous variation) [35]. The stoichiometric ratio was found to be 1 uric acid: $2 \mathrm{Fe}^{3+}$, which is the stoichiometry of the reaction. Simoyi and co-workers [36] described allantoin as the oxidation product of uric acid. The reaction of uric acid with $\mathrm{Fe}^{3+}$ and 1,10-phenanthroline is illustrated in Fig. 2. In preliminary tests of the digital image detection method, the green channel of the RGB color format was selected for use in the colorimetric analyses, due its higher sensitivity.

\subsubsection{Optimization of variables}

The influence of temperature and the order of addition of the reagents on color development were investigated. The best spot color uniformity and intensity was achieved when the $\mathrm{Fe}^{3+}$ solution was added first, followed by the uric acid and 1,10-phenanthroline solutions.

Iron (III) can undergo hydrolysis in an aqueous medium [37], so this solution was prepared under acid conditions, with $\mathrm{H}^{+}$concentrations of $0.5,0.75$, and $1.0 \mathrm{~mol} \mathrm{~L}^{-1}$. No significant differences in the analytical response were observed with the different acid concentrations, so the preparation was performed using $0.5 \mathrm{~mol} \mathrm{~L}^{-1}$ of $\mathrm{H}^{+}$in order to minimize reagent use.

The complexometric reaction between $\mathrm{Fe}^{2+}$ and 1,10phenanthroline is quantitative in the $\mathrm{pH}$ range from 2 to 9 [34]. The metal and complexation solutions were added separately, in order to avoid reaction between the reagents and consequent formation of the colored product, while the $\mathrm{Fe}^{3+}$ solution was prepared in acid medium. The 1,10-phenanthroline solution was therefore prepared using sodium acetate, and mixing of the two solutions resulted in the formation of buffer solutions with $\mathrm{pH}$ of $4.0,4.5$, and 5.0. The variation of $\mathrm{pH}$ did not cause any significant alteration in the analytical response, so $\mathrm{pH} 4.0$ was selected in order to minimize reagent use.

There was an enhancement of $20 \%$ in the analytical response when the reaction medium was heated for $60 \mathrm{~s}$ using a domestic hair dryer at minimum power. Consequently, a full factorial design $\left(2^{3}\right)$ was used to identify the parameters that had the greatest influence on the reaction, considering the heating time and the concentrations of 1,10-phenanthroline and $\mathrm{Fe}^{3+}$. The factorial design matrix is described in Table S1 and the results are shown as a Pareto chart in Fig. S1, where the dashed vertical line indicates the 95\% statistical significance limit. Any bar that exceeds this line indicates a significant influence on the analytical signal. The $\mathrm{Fe}^{3+}$ concentration and the heating time showed significant positive influences, indicating that the best results were obtained when these factors were employed at a high level. The 1,10phenanthroline concentration showed no significant influence.

The heating time and $\mathrm{Fe}^{3+}$ concentration were selected to perform a central composite design to obtain the optimal experimental conditions, since they showed significant influences on the reaction. The 1,10-phenanthroline concentration was maintained at a low level, since this provided better results.

For the central composite design, these two factors were combined at five levels, with five replicates of the central point (Table S2). Fig. S2 illustrates the three-dimensional response surface graph obtained from the experimental data shown in Table S2. The quadratic regression model could be described by the equation: $\mathrm{A}_{\mathrm{G}}=-0.0914+0.00173 \mathrm{t}-0.00002 \mathrm{t}^{2}+4.600 \mathrm{C}_{\mathrm{Fe}}^{3+}-49.417$ $\mathrm{C}^{23+} \mathrm{Fe}-0.00377 \mathrm{t} \mathrm{C}_{\mathrm{Fe}}^{3+}$. This equation provided critical values of $47 \mathrm{~s}$ for the heating time and $0.0448 \mathrm{~mol} \mathrm{~L}^{-1}$ for the $\mathrm{Fe}^{3+}$ concentration. The heating time used for the measurements was $50 \mathrm{~s}$, because it showed no significant difference to the critical value. Under these experimental conditions, the optical signal obtained for the colored product showed no significant change for at least $75 \mathrm{~min}$.

The iron and 1,10-phenanthroline solutions could not be added to the same zone, because a colored product was formed in the absence of the analyte. Therefore, two different conditions were evaluated: (A) with the iron solution spotted in the testing zone and the 1,10-phenanthroline solution spotted in the uptake zone, and (B) with the iron solution spotted in the uptake zone and the 1,10phenanthroline solution spotted in the testing zone. The best result was obtained using condition $\mathrm{A}$, because the coloring of the product was more uniform, decreasing the half-moon shape of the stain. The optimized reagent volumes added to the two zones were $2 \mu \mathrm{L}$ of each reagent, due to the greater effective intensity of the product in the testing zone.

\subsubsection{Analytical curve and figures of merit}

After establishment of the best experimental conditions by optimization of the variables, an analytical curve was constructed for uric acid in the concentration range from $50 \mathrm{mg} \mathrm{L}^{-1}$ to $500 \mathrm{mg} \mathrm{L}^{-1}$, by appropriate dilution of a stock standard solution. A linear relationship was obtained between the uric acid concentration and the green channel effective intensity $\left(A_{G}\right)$, described by $A_{G}=0.0165+0.000368 C_{U A}$, with $R=0.999(n=3)$. The repeatability was evaluated from the relative standard deviations [38] obtained for intra-day and inter-day measurements at two concentrations; for a $200 \mathrm{mg} \mathrm{L}^{-1}$ solution of uric acid, the \%RSD values were $5.8 \%$ and $6.7 \%$, respectively, while the values for a $400 \mathrm{mg} \mathrm{L}^{-1}$ solution were $4.0 \%$ and $8.3 \%$, respectively. These results were considered acceptable [39], demonstrating that the proposed method was repeatable and that the analytical device could be used for the determination of uric acid in urine.

The limits of detection (LOD) and quantification (LOQ) were determined according to the IUPAC [40] recommendations: $\mathrm{LOD}=3^{*} \sigma / \mathrm{S}$ and $\mathrm{LOQ}=10^{*} \sigma / \mathrm{S}$, where $\sigma$ is the standard deviation of measurements of the blank $(\mathrm{n}=10)$ and $\mathrm{S}$ is the slope of the linear

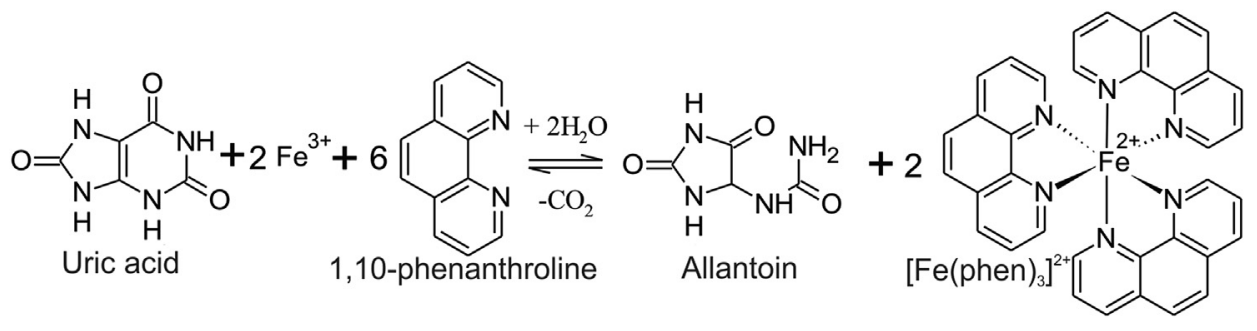

Fig. 2. Overall reaction of uric acid with $\mathrm{Fe}^{3+}$ and 1,10-phenanthroline. 
range. The LOD and LOQ values were $16.5 \mathrm{mg} \mathrm{L}^{-1}$ and $54.9 \mathrm{mg} \mathrm{L}^{-1}$, respectively. The normal concentration of uric acid in urine ranges from 370 to $2500 \mathrm{mg} \mathrm{L}^{-1}$ in males and females. Therefore, the proposed method provided sufficient sensitivity for the determination of uric acid in human urine [41].

In addition, a semi-quantitative visual determination can be performed by comparison with a color palette (Fig. 3), when no scanner is available.

\subsection{Creatinine method}

The colorimetric determination of creatinine was based on the Jaffé reaction in an alkaline medium, where picric acid produces an orange compound (Janovsky complex) in the presence of creatinine [33] (Fig. 4). In preliminary experiments, the green channel of the RGB color format was selected for use in the colorimetric analysis, due its higher sensitivity.

\subsubsection{Optimization of variables}

Evaluation was made of the influence of temperature and the order of addition of the reagents on color development. The best color uniformity and intensity of the spot was achieved when the picrate solution was added first, followed by the creatinine solution. As Jaffé reaction is temperature dependent [33], the experiments showed an enhancement of $25 \%$ in the analytical response when the reaction medium was heated for $60 \mathrm{~s}$ using a domestic hair dryer at minimum power.

Multivariate analysis was employed to optimize the experimental variables. A full factorial design $\left(2^{3}\right)$ was used to obtain the parameters that were most influential for the reaction, considering the heating time and the concentrations of picric acid and hydroxide. The experimental design matrix is described in Table S3 and the results are illustrated in the Pareto chart shown in Fig. S3. The dashed vertical line in Fig. S3 indicates the 95\% statistical significance limit. The heating time showed a significant positive influence, indicating that the best results were obtained when this factor was employed at a high level. The hydroxide and picric acid concentrations showing no significant influence. Therefore, the heating time selected for the creatinine reaction was $50 \mathrm{~s}$, as used in the uric acid determination, because the heating period had to be the same for both analytes since the determinations were performed with the same device. Under this condition, there was no significant difference from the results obtained using heating for $60 \mathrm{~s}$.

When the optimized conditions obtained from the response surface experiments were applied using the $\mu \mathrm{PAD}$, the reaction did not occur immediately after heating. Therefore, the strategy used to obtain similar coloring in the spot test was to increase the

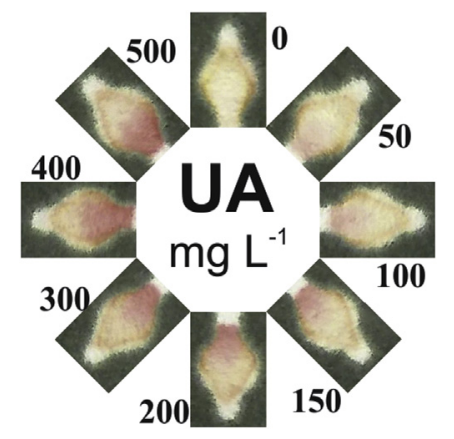

Fig. 3. Color palette for semi-quantitative visual determination of uric acid. (For interpretation of the references to colour in this figure legend, the reader is referred to the web version of this article.)<smiles>C[14C](=O)[O-]</smiles>

Fig. 4. Jaffé reaction between creatinine and picric acid in an alkaline medium.

hydroxide concentration and decrease the picric acid concentration. This approach could be used because neither $\mathrm{C}_{\mathrm{OH}^{-}}$nor $\mathrm{C}_{\mathrm{PA}}$ had a significant influence on the reaction (Fig. S3). In addition, as $\mathrm{COH}^{-}$ had a negative impact and $C_{P A}$ had a positive impact, the increase of one and decrease of the other did not significantly alter the analytical response.

The hydroxide concentration was therefore increased to $1.00 \mathrm{~mol} \mathrm{~L}^{-1}$, at which a plateau of maximum effective intensity was reached using a smaller volume of reagent $(2 \mu \mathrm{L})$, compared to when $\mathrm{C}_{\mathrm{OH}^{-}}$of $0.900 \mathrm{~mol} \mathrm{~L}^{-1}$ was used $(3 \mu \mathrm{L})$. The picric acid concentration was decreased to $0.0100 \mathrm{~mol} \mathrm{~L}^{-1}$, due its lower solubility in a more alkaline medium. Under these conditions, the color development occurred immediately after heating and the color remained stable for at least $3 \mathrm{~h}$.

Similarly to that for uric acid, identification of the best zone for reagent addition was necessary. When the reagent was deposited in the uptake zone, the color of the product was more uniform and occupied the entire zone, decreasing the half-moon shaped stain.

\subsubsection{Analytical curve and figures of merit}

After optimization of the variables, the proposed creatinine methodology was evaluated using the same parameters employed for the uric acid methodology. A linear relationship was obtained between effective intensity in green channel $\left(A_{G}\right)$ and creatinine concentration, in the range from $50 \mathrm{mg} \mathrm{L}^{-1}$ to $600 \mathrm{mg} \mathrm{L}^{-1}$, described by $\mathrm{A}_{\mathrm{G}}=0.223+0.000401 \mathrm{C}_{\mathrm{CRN}}$, with $\mathrm{R}=0.999(\mathrm{n}=3)$. The LOD and LOQ values obtained according to the IUPAC [40] recommendations $(\mathrm{n}=10)$ were $15.7 \mathrm{mg} \mathrm{L}^{-1}$ and $52.4 \mathrm{mg} \mathrm{L}^{-1}$, respectively.

The repeatability was evaluated using intra-day and inter-day relative standard deviations (\%RSD) obtained for measurements at two concentrations. For a $150 \mathrm{mg} \mathrm{L}^{-1}$ solution of creatinine, the $\%$ RSD values were $3.3 \%$ and $3.8 \%$, respectively, while the values for a $400 \mathrm{mg} \mathrm{L}^{-1}$ solution were $2.6 \%$ and $4.6 \%$, respectively. These results showed that the proposed method was repeatable and could be used for the determination of creatinine in urine using the analytical device. The normal levels of creatinine in urine range from 400 to $3000 \mathrm{mg} \mathrm{L}^{-1}$ in males and from 370 to $2500 \mathrm{mg} \mathrm{L}^{-1}$ in females. Therefore, the proposed method provided sufficient sensitivity for the determination of creatinine in human urine [42]. In addition, a semi-quantitative visual determination could be performed by comparison with a color palette (Fig. 5), when no scanner is available.

\subsection{Study of interferences}

Possible interferences from compounds present in artificial and natural urine were evaluated using the interference factor (IF), which is calculated as the ratio of the analyte signal in the presence of interferents to the signal in the absence of them: $\mathrm{IF}=\mathrm{A}_{\mathrm{G}}$ (analyte + interferent) $/ \mathrm{A}_{\mathrm{G}}$ (analyte) [43]. Solutions containing $200 \mathrm{mg} \mathrm{L}^{-1}$ of the analyte together with each possible interferent at the same concentration, a 10-fold greater concentration 


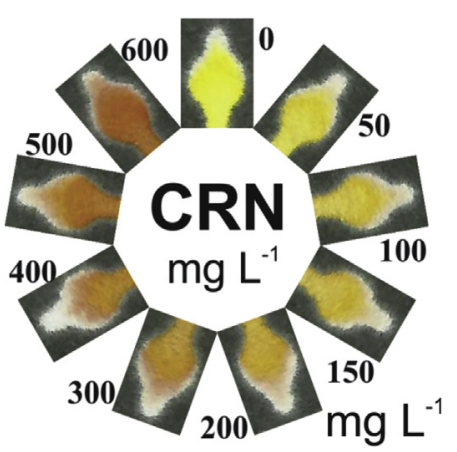

Fig. 5. Color palette for semi-quantitative visual determination of creatinine. (For interpretation of the references to colour in this figure legend, the reader is referred to the web version of this article.)

(urea), or a 25-fold lower concentration (bilirubin) were evaluated under the same conditions described in Section 2.4, obtained using the experimental design.

For all the compounds evaluated, the interference factors, at the concentrations described above, were between 0.96 and 1.04 for the two analytes (Table S4), with the exception of the interference of ascorbic acid in the uric acid determination. Since these values were less than 5\% (except for the positive interference of ascorbic acid in the uric acid determination), it was considered that interferences were minimal [44]. The effect of ascorbic acid was expected, due to its reducing potential.

Ascorbic acid can be easily eliminated by bubbling air through the sample. For the natural urines, passage of air through the sample for 20 min was sufficient to oxidize the ascorbic acid, resulting in a decrease of the interference factor for this compound to 1.02 .

\subsection{Application to artificial and natural urine samples}

Seven samples containing creatinine and uric acid were analyzed by the proposed methods and the comparative technique [3]. These samples consisted of three artificial urines (A-C) and four natural urines (D-G). The results obtained for the two methods were compared statistically using the paired Student's t-test (at the $95 \%$ confidence level). The calculated t-values did not exceed the critical values, showing that there were no significant differences between the results obtained using the two methods (Table 1), hence confirming the accuracy of the proposed method.

The information presented in Table 2 shows that compared to chromatographic techniques, the proposed method is safer for the operator and the environment, because it avoids the use of toxic organic solvents, such as methanol and acetonitrile, and generates a minimal quantity of solid residue that can be easily incinerated. A cost comparison between the proposed method and a chromatography method (Table S5) showed that an analysis by the paper platform is low cost. Determinations of creatinine and uric acid can therefore be performed using a method that is faster, less expensive, simpler, more portable, and easier to apply, compared to the comparative method.

Other methods have been reported for uric acid determination using a $\mu \mathrm{PAD}$, employing enzymatic reactions [14,15], and gold nanoparticles [16]. Enzymatic reactions are known to provide high specificity, but can exhibit low reproducibility, which hinders their use. The paper method based on gold nanoparticles (AuNPs) was only suitable for semi-quantitative tests, and there have been no applications of the methodology using real samples.

The only method for the quantification of creatinine using a paper platform (but not employing a specifically paper-based microfluidic analytical device) was described by Sittiwong and Unob [9]. The procedure involved the extraction of urinary creatinine on paper in an acid medium, with subsequent washes and addition of the chromogenic reagent. The extraction in an acid medium, prior to the colorimetric reaction, made it impossible to simultaneously determine uric acid using the same paper platform, because the entire paper was used for the creatinine determination and the sample was exposed to acid conditions, under which urate is converted to insoluble uric acid that is not available for the reaction. In the case of the present proposed method, the analysis of creatinine is simple and does not require any extraction steps.

\section{Conclusions}

This work describes the development of an validated $\mu$ PAD for the simultaneous quantification of two important renal biomarkers in urine. We used chemometrics to optimize conditions for the reactions and the design of the device, and a chromatography method to validate the proposed platform. Due to the simplicity of the developed $\mu \mathrm{PAD}$, a semi-skilled person in a local without minimal infrastructure can use the test to evaluate the renal function.

This new platform for quantification of uric acid and creatinine in urine provides relevant information about kidney failure-a silent disease with a growth number of cases-and gout. Other diseases like diabetes, Lesch-Nyan disease, high blood pressure, and heart disease could also be evaluated in similar tests. The levels of several compounds are expressed clinically as a ratio to the creatinine concentration. For example, the uric acid/creatinine ratio could be an additional marker of perinatal asphyxia in newborns [45] and gout patients [46]. Using the clinical result as a relative

Table 1

Simultaneous determination of creatinine (CRN) and uric acid (UA) in urine samples.

\begin{tabular}{|c|c|c|c|c|c|c|}
\hline \multirow[t]{2}{*}{ Sample } & \multicolumn{2}{|l|}{$\begin{array}{l}\text { CRN concentration }{ }^{\mathrm{a}} \\
\left(\mathrm{mg} \mathrm{L}^{-1}\right)\end{array}$} & \multirow[t]{2}{*}{$t$-test ${ }^{\mathrm{b}}$} & \multicolumn{2}{|l|}{$\begin{array}{l}\text { UA concentration } \\
\left(\mathrm{mg} \mathrm{L}^{-1}\right)\end{array}$} & \multirow[t]{2}{*}{$t$-test $^{\mathrm{b}}$} \\
\hline & Proposed method & Comparative method [3] & & Proposed method & Comparative method [3] & \\
\hline $1^{\mathrm{c}}$ & $281 \pm 14$ & $304 \pm 0$ & 2.816 & $214 \pm 21$ & $225 \pm 0$ & 0.878 \\
\hline $2^{c}$ & $736 \pm 6$ & $748 \pm 0$ & 2.959 & $585 \pm 31$ & $599 \pm 0$ & 0.758 \\
\hline $3^{c}$ & $1202 \pm 41$ & $1211 \pm 1$ & 0.393 & $918 \pm 72$ & $908 \pm 0$ & 0.234 \\
\hline $4^{\mathrm{d}}$ & $1009 \pm 77$ & $976 \pm 15$ & 0.628 & $356 \pm 33$ & $339 \pm 3$ & 0.805 \\
\hline $5^{\mathrm{d}}$ & $1143 \pm 61$ & $1154 \pm 1$ & 0.302 & $434 \pm 36$ & $443 \pm 7$ & 0.363 \\
\hline $6^{\mathrm{d}}$ & $1049 \pm 30$ & $1045 \pm 0$ & 0.237 & $216 \pm 15$ & $226 \pm 5$ & 1.106 \\
\hline $7^{d}$ & $1627 \pm 45$ & $1630 \pm 8$ & 0.131 & $338 \pm 22$ & $338 \pm 16$ & 0.023 \\
\hline
\end{tabular}

\footnotetext{
a Average of three determinations.

b The critical value at the 95\% confidence level and with two degrees of freedom was 4.303 .

c Artificial urine samples.

d Natural urine samples.
} 
Table 2

Comparison of parameters of the proposed and previously reported methodologies for the simultaneous determination of creatinine and uric acid.

\begin{tabular}{|c|c|c|}
\hline Parameter & Proposed method & Comparative method [3] \\
\hline Organic solvent used & - & Methanol \\
\hline Residue formation & Solid ( $\mu$ PAD), incinerable & Liquid, 75 mL of methanol (75\%) \\
\hline Sample preparation & $\begin{array}{l}\text { Simple, fast, cheap, no sophisticated instrumentation required } \\
\text { (dilution and air bubbling) }\end{array}$ & $\begin{array}{l}\text { Simple, expensive, sophisticated instrumentation required } \\
\text { (dilution, centrifugation, filtration) }\end{array}$ \\
\hline Reagent mass used & $90 \mathrm{mg}$ for CRN analysis and $195 \mathrm{mg}$ for UA analysis & - \\
\hline Reagent volume & $6 \mu \mathrm{L}$ (aqueous solution) & - \\
\hline Solvent volume & - & $\sim 75 \mathrm{~mL}$ of methanol: $\mathrm{H}_{2} \mathrm{O}(75: 25)$ \\
\hline Sample volume & $10 \mu \mathrm{L}$ & $20 \mu \mathrm{L}$ \\
\hline Analysis time & $12.5 \mathrm{~min} / \mathrm{sample}$ & $30 \mathrm{~min} / \mathrm{sample}$ \\
\hline Analysis cost & Low cost & Higher cost \\
\hline
\end{tabular}

concentration compensates for the urine volume [47], and also avoids adulteration by dilution [42]. Therefore, in addition to the number of $\mu$ PADs described in the literature for glucose [22], protein [22], nitrite [23], aldehydes [24], beta-hydroxybutyrate [25], uric acid [15], and cholesterol [26], with the proposed device, the methods of clinical analysis are increased, making possible the evaluation of several diseases in a single $\mu \mathrm{PAD}$ and compensating the urine dilution.

The use of $\mu$ PADs with colorimetric detection provides a simple, portable, easy to use, eco-friendly, and inexpensive analytical test for the determination of creatinine and uric acid. The platform is an attractive alternative to the conventional chromatographic methodologies used in the prevention and diagnosis of renal failure.

\section{Acknowledgements}

The authors are grateful for the financial support provided by the São Paulo Research Foundation [FAPESP/CAPES Grant \#s 2014/ 17749-7 and FAPESP 2015/21733-1] and the National Council for Technological and Scientific Development of Brazil [CNPq Grant \#s 132646/2014-5 and 308788/2015-0].

\section{Appendix A. Supplementary data}

Supplementary data related to this article can be found at https://doi.org/10.1016/j.aca.2017.10.018.

\section{References}

[1] C.A. Burtis, Tietz Fundamentals of Clinical Chemistry, fifth ed., W. B. Saunders Company, Philadelphia, 2001.

[2] P. Derezinski, A. Klupczynska, W. Sawicki, Z.J. Kokot, Creatinine determination in urine by liquid chromatography-electrospray ionization-tandem mass spectrometry method, Acta Pol. Pharm. - Drug Res. 73 (2016) 303-313.

[3] L.-W. Xiang, J. Li, J.-M. Lin, H.-F. Li, Determination of gouty arthritis' biomarkers in human urine using reversed-phase high-performance liquid chromatography, J. Pharm. Anal. 4 (2014) 153-158.

[4] D. Remane, S. Grunwald, H. Hoeke, A. Mueller, S. Roeder, M. von Bergen, D.K. Wissenbach, Validation of a multi-analyte HPLC-DAD method for determination of uric acid, creatinine, homovanillic acid, niacinamide, hippuric acid, indole-3-acetic acid and 2-methylhippuric acid in human urine, J. Chromatogr. B 998-999 (2015) 40-44.

[5] A.K. Parmar, N.N. Valand, K.B. Solanki, S.K. Menon, Picric acid capped silver nanoparticles as a probe for colorimetric sensing of creatinine in human blood and cerebrospinal fluid samples, Analyst 141 (2016) 1488-1498.

[6] T. Songjaroen, T. Maturos, A. Sappat, A. Tuantranont, W. Laiwattanapaisal, Portable microfluidic system for determination of urinary creatinine, Anal. Chim. Acta 647 (2009) 78-83.

[7] C.L.S. Chagas, F.R. de Souza, T.M.G. Cardoso, R.C. Moreira, J.A.F. da Silva, D.P. de Jesus, W.K.T. Coltro, A fully disposable paper-based electrophoresis microchip with integrated pencil-drawn electrodes for contactless conductivity detection, Anal. Methods 8 (2016) 6682-6686.

[8] V. Pavlíček, P. Tůma, J. Matějčková, E. Samcová, Very fast electrophoretic determination of creatinine and uric acid in human urine using a combination of two capillaries with different internal diameters, Electrophoresis 35 (2014) 956-961.

[9] J. Sittiwong, F. Unob, Paper-based platform for urinary creatinine detection, Anal. Sci. 32 (2016) 639-643.
[10] D. Lakshmi, M.J. Whitcombe, F. Davis, P.S. Sharma, B.B. Prasad, Electrochemical detection of uric acid in mixed and clinical samples: a review, Electroanalysis 23 (2011) 305-320.

[11] R.M.R. Bastos, M.T.B. Teixeira, A. Chaoubah, R.V. Bastos, M.G. Bastos, Hyperuricemia: a marker of preclinical chronic kidney disease? J. Bras. Nefrol. 31 (2009) 32-38.

[12] H. Khajehsharifi, E. Pourbasheer, H. Tavallali, S. Sarvi, M. Sadeghi, The comparison of partial least squares and principal component regression in simultaneous spectrophotometric determination of ascorbic acid, dopamine and uric acid in real samples, Arab. J. Chem. 10 (2017) S3451-S3458.

[13] J. Guo, Uric acid monitoring with a smartphone as the electrochemical analyzer, Anal. Chem. 88 (2016) 11986-11989.

[14] W. Dungchai, O. Chailapakul, C.S. Henry, Use of multiple colorimetric in dicators for paper-based microfluidic devices, Anal. Chim. Acta 674 (2010) 227-233.

[15] E.F.M. Gabriel, P.T. Garcia, T.M.G. Cardoso, F.M. Lopes, F.T. Martins W.K.T. Coltro, Highly sensitive colorimetric detection of glucose and uric acid in biological fluids using chitosan-modified paper microfluidic devices, Analyst 141 (2016) 4749-4756.

[16] A. Kumar, A. Hens, R.K. Arun, M. Chatterjee, K. Mahato, K. Layek, N. Chanda A paper based microfluidic device for easy detection of uric acid using positively charged gold nanoparticles, Analyst 140 (2015) 1817-1821.

[17] P.T. Anastas, M.M. Kirchhoff, Origins, current status, and future challenges of green chemistry, Acc. Chem. Res. 35 (2002) 686-694.

[18] G.G. Morbioli, T. Mazzu-Nascimento, A.M. Stockton, E. Carrilho, Technical aspects and challenges of colorimetric detection with microfluidic paperbased analytical devices ( $\mu$ PADs) - a review, Anal. Chim. Acta 970 (2017) $1-22$.

[19] E.L. Rossini, M.I. Milani, L. Pezza, H.R. Pezza, A new eco-friendly methodology for the determination of Amaranth dye in foodstuffs using diffuse reflectance spectroscopy, Anal. Methods 8 (2016) 4086-4092.

[20] K. Yamada, H. Shibata, K. Suzuki, D. Citterio, Toward practical application of paper-based microfluidics for medical diagnostics: state-of-the-art and challenges, Lab. Chip (2017) 1206-1249.

[21] D.M. Cate, J.a Adkins, J. Mettakoonpitak, C.S. Henry, Recent developments in paper-based microfluidic devices, Anal. Chem. 87 (2015) 19-41.

[22] A.W. Martinez, S.T. Phillips, G.M. Whitesides, E. Carrilho, Diagnostics for the developing world: microfluidic paper-based analytical devices, Anal. Chem. 82 (2010) 3-10

[23] S.A. Bhakta, R. Borba, M. Taba, C.D. Garcia, E. Carrilho, Determination of nitrite in saliva using microfluidic paper-based analytical devices, Anal. Chim. Acta 809 (2014) 117-122.

[24] A.N. Ramdzan, M. In, Development of a microfluidic paper-based analytical device for the determination of salivary aldehydes, Anal. Chim. Acta 919 (2016) 47-54.

[25] C.C. Wang, J.W. Hennek, A. Ainla, A.A. Kumar, W.J. Lan, J. Im, B.S. Smith, M. Zhao, G.M. Whitesides, A paper-based pop-up electrochemical device for analysis of beta-hydroxybutyrate, Anal. Chem. 88 (2016) 6326-6333.

[26] S. Nantaphol, O. Chailapakul, W. Siangproh, A novel paper-based device coupled with a silver nanoparticle-modified boron-doped diamond electrode for cholesterol detection, Anal. Chim. Acta 891 (2015) 136-143.

[27] D.C. Harris, Quantitative Chemical Analysis, eighth ed., W. H. Freeman and Company, New York, 2010.

[28] N. Laube, B. Mohr, A. Hesse, Laser-probe-based investigation of the evolution of particle size distributions of calcium oxalate particles formed in artificial urines, J. Cryst. Growth 233 (2001) 367-374.

[29] E. Carrilho, A.W. Martinez, G.M. Whitesides, Wax printing - a simple micropatterning process for paper-based microfluidics, Anal. Chem. 81 (2009) $7091-7095$.

[30] A. Abbaspour, A. Khajehzadeh, A. Ghaffarinejad, A simple and cost-effective method, as an appropriate alternative for visible spectrophotometry: development of a dopamine biosensor,, Analyst 134 (2009) 1692-1698.

[31] A.W. Martinez, S.T. Phillips, M.J. Butte, G.M. Whitesides, Patterned paper as a platform for inexpensive, low-volume, portable bioassays, Angew. Chem. - Int. Ed. 46 (2007) 1318-1320.

[32] E. Evans, E.F.M. Gabriel, W.K.T. Coltro, C.D. Garcia, Rational selection of 
substrates to improve color intensity and uniformity on microfluidic paperbased analytical devices, Analyst 139 (2014) 2127-2132.

[33] S. Narayanan, H. Appleton, Creatinine: a review, Clin. Chem. 26 (1980) 1119-1126.

[34] E.B. Sandell, Iron, in: Color. Determ. Traces Met., third ed., Interscience Publishers, New York, 1959, pp. 522-542.

[35] M.S. Suresha, M.S.A. Galil, M.A. Sathish, M.S.Y. Kumar, G. Nagendrappa, A new spectrophotometric method for hydrogen sulphide through electrolytically generated Mn (III) with o-tolidine, E-J. Chem. 5 (2008) 93-99.

[36] M.F. Simoyi, E. Falkkenstein, K. Van Dyke, K.P. Blemings, H. Klandorf, Allantoin, the oxidation product of uric acid is present in chicken and Turkey plasma, Comp. Biochem. Physiol. - Part B 135 (2003) 325-335.

[37] C.F.J. Baes, R.E. Mesmer, The Hydrolysis of Cations, John Wiley \& Sons, New York, 1976.

[38] I. Taverniers, M. De Loose, E. Van Bockstaele, Trends in quality in the analytica laboratory. II. Analytical method validation and quality assurance, Trac. Trends Anal. Chem. 23 (2004) 535-552.

[39] L. Huber, H.-P. Gmbh, Validation of analytical methods: review and strategy, LC/GC Mag. (1999) 1-17.

[40] G.L. Long, J.D. Winefordner, Limit of detection, Anal. Chem. 55 (1983)
A712-A724

[41] J. Ballesta-Claver, I.F. Díaz Ortega, M.C. Valencia-Mirón, L.F. Capitán-Vallvey, Disposable luminol copolymer-based biosensor for uric acid in urine, Anal. Chim. Acta 702 (2011) 254-261.

[42] W.R. De Araújo, M.O. Salles, T.R.L.C. Paixão, Development of an enzymeless electroanalytical method for the indirect detection of creatinine in urine samples, Sensors Actuators, B Chem. 173 (2012) 847-851.

[43] J.C. De Andrade, R.E. Bruns, Catalytic Determination of Molybdenum (VI) in Plants Using Mono-segmented Continuous-flow Analysis and Spectrophotometric Detection, vol. 118, 1993.

[44] E.S. Almeida, S.D.E.P. Eiras, Avaliação do emprego de 8-hidroxiquinolina e mistura homogênea dos solventes água-ethanol-clorofórmio para a determinação de íons Al3+, Horiz. Científico 3 (2009) 1-15.

[45] K.P. Patel, M.G. Makadia, V.I. Patel, H.N. Nilayangode, S.M. Nimbalkar, Urinary uric acid/creatinine ratio - a marker for perinatal asphyxia, J. Clin. Diagn. Res. 11 (2017) 10-12.

[46] Y. Nishida, Relation between creatinine and uric acid excretion, Ann. Rheum. Dis. 51 (1992) 101-102.

[47] C.-C. Lin, C.-C. Tseng, T.-K. Chuang, D.-S. Lee, G.-B. Lee, Urine analysis in microfluidic devices, Analyst 136 (2011) 2669-2688. 